\title{
Effect of cytokines on the epithelial function of the human colon carcinoma cell line HT29 cl 19A
}

\author{
A Hiribarren, M Heyman, A L'Helgouac'h, J F Desjeux
}

\begin{abstract}
In various intestinal diseases, lymphoid cell infiltration of the lamina propria might be an important factor causing intestinal dysfunction through cytokine release. The effects of such cytokines were therefore measured on chloride secretion and macromolecular transport in intestinal HT29 cl 19A cells. Cells were grown on transwell filters and serosally exposed for two to 48 hours to $1 \%$ or $5 \%$ concentrations of phytohaemagglutinin (PHA) activated or nonactivated healthy human mononuclear cell culture supernatants. These supernatants were tested for their interferon $\gamma$ (IFN $\gamma$ ), tumour necrosis factor $\alpha$ (TNF $\alpha$ ), and interleukin 6 (IL6) concentration. The mean (SE) were 4.72 $(1.63), 3 \cdot 17(0 \cdot 14)$, and $4.47(1 \cdot 12) \mathrm{ng} / \mathrm{ml}$ in activated supernatants. Intestinal function was studied in Ussing chambers: chloride secretion was assessed from the variations in short circuit current, and epithelial barrier capacity was monitored by the electrical resistance of the HT29 cl 19A cell monolayers and by measuring intact or degraded fluxes of the macromolecular tracer horseradish peroxidase. Release of lactate dehydrogenase (LDH) in the presence of various concentrations of cytokines was assessed as a test for cellular injury. The results indicate that serosal cytokines do not directly stimulate short circuit current. Long term (48 hours) exposure, however, significantly reduced both short circuit current $\left(6.79(0.65) v 2.90(1.16) \mu \mathrm{A} / \mathrm{cm}^{2}\right.$ in control $v$ treated cells) and barrier capacity as shown by the decrease in resistance of the HT29 cl 19A cell monolayers from $158(10)$ to 36 (9) ohms.cm ${ }^{2}$, and the increase in intact fluxes from 167 (33) in controls to 874 (206) $\mathrm{ng}$ / h.cm ${ }^{2}$, in cytokine rich supernatant treated cells and in degraded fluxes from 1113 (114) to 2327 (234) $\mathrm{ng} / \mathrm{h}_{\mathrm{cm}} \mathrm{cm}^{2}$. This decreased barrier capacity was associated with an increase in release of LDH $(21.7(1.2)$ and $43.6(2.0) \mathrm{UI}$ h.cm ${ }^{2}$ in $1 \%$ and $5 \%$ cytokine treated monolayers $v 10.8(2.1) \mathrm{UI} / \mathrm{h} . \mathrm{cm}^{2}$ in control monolayers). The results indicate that cytokines do not directly stimulate intestinal chloride secretion but that prolonged exposure to these agents reduces both electrolyte transport and barrier capacity to macromolecules through cellular and paracellular pathways.

(Gut 1993; 34: 616-620)
\end{abstract}

In intestinal diseases such as food allergy, epithelial dysfunctions, mainly in secretion of water and electrolytes, and increased permeability, are associated with abnormal infiltration of mast cells and lymphocytes. The role of mast cells in activating chloride secretion has been clearly established $^{1-3}:$ antigen induced mast cell degranulation leads to the release of a large number of mediators, some of which including histamine, prostaglandins, and platelet activating factor have been shown to activate chloride secretion. Also, in cow's milk allergy of human infants, intestinal biopsies are infiltrated with lymphocytes. We found such biopsies with an enhanced short circuit current, possibly due to electrogenic chloride secretion, and with increased permeability to the intact and degraded macromolecule horseradish peroxidase. ${ }^{4}$ Cytokine release inside the lamina propria might play an important part in the epithelial dysfunctions found in food allergy, but there are few studies on this point. Previous reports have shown that cytokines might act on enterocyte functions - for example, the interleukins IL1 and IL3 were shown to stimulate short circuit current in chicken and rabbit small intestine,${ }^{56}$ and interferon $\gamma(\mathrm{IFN} \gamma)$ was implicated in reducing electrical resistance and increasing small molecule permeability in the T 84 cell line. ${ }^{7}$ Interferon $\gamma$ combined with tumour necrosis factor $\alpha$ (TNF $\alpha$ ) has also been shown to be cytotoxic to HT29 cells. ${ }^{8}$ These findings might explain certain epithelial dysfunctions such as the increased permeability to macromolecules or the increased electrogenic $\mathrm{Cl}^{-}$secretion found in cow's milk allergy and other intestinal diseases. The aim of our study was therefore to investigate the effect of phytohaemagglutinin (PHA) activated mononuclear cell culture supernatants containing cytokines on the epithelial function of the human colon carcinoma cell line HT29 cl 19A.

\section{Methods}

MONONUCLEAR CELL CULTURE SUPERNATANTS Mononuclear cells, mainly lymphocytes, were extracted from blood samples from four healthy subjects. These were separated on a Ficoll gradient (MSL, Eurobio, France), washed three times with buffered saline, resuspended in RPMI 1640 (Eurobio) containing $10 \%$ heat inactivated human $A B$ serum, $100 \mathrm{U} / \mathrm{ml}$ of penicillin and streptomycin and $4 \mathrm{mM}$ of glutamine, and adjusted to $4 \times 10^{6}$ cells $/ \mathrm{ml}$. Cells were cultured for 24 hours in the presence or absence of $10 \mu \mathrm{g} /$ ml phytohaemaglutinin (Sigma, France). Supernatants from phytohaemagglutinin activated cell cultures were added, at a final concentration of $1 \%$ or $5 \%$, to the serosal compartment of the polycarbonate transwell filters on which the HT29 cl 19A cells were grown, and left for two or 48 hours. Control experiments were conducted with non-activated cell culture supernatants in which phytohaemagglutinin was subsequently added to test that phytohaemagglutinin by itself 
had no effect on HT29 cl 19A intestinal cells. The filters were then mounted in Ussing chambers for further measurements of epithelial function.

The mononuclear cell culture supernatants were assayed for TNF $\alpha$, IFN $\gamma$, and IL6 to characterise their cytokine pattern more clearly. The enzyme linked immunosorbent assay (ELISA) kit for IFN $\gamma$ and TNF $\alpha$ and Intertest 6 for IL6 (Genzyme, Tebu, France) were used to measure the cytokine concentration in supernatant fluid. The limit of sensitivity was $10 \mathrm{pg} / \mathrm{ml}$ for IFN $\gamma$ and $3 \mathrm{pg} / \mathrm{ml}$ for IL6 and TNF $\alpha$.

\section{CULTURE OF HT29 CL 19A}

We used the HT29 cl 19A cell line, cloned from the human colon carcinoma cell line HT29 by Augeron and Laboisse. ${ }^{9}$ The cells were obtained from Dr C Laboisse (INSERM U239, Paris) at passage 10 and used until passage 25 .

HT29 cl 19A cells were cultured at $37^{\circ}$ in Dulbecco's Modified Eagle Medium (Boehringer, Mannheim, Germany) containing $10 \%$ heat inactivated fetal calf serum and $4 \mathrm{mM}$ of glutamine in a humidified atmosphere of $6 \%$ $\mathrm{CO}_{2} 94 \%$ air. Cells were routinely checked for mycoplasma contamination by Chen's method. ${ }^{10}$ They were passaged every week and seeded at $10^{6}$ cells $25 \mathrm{~cm}^{2}$ in the absence of antibiotics. For experimental purposes, cells were cultured in the presence of $100 \mathrm{U} / \mathrm{ml}$ of penicillin and streptomycin. Polycarbonate $24.5 \mathrm{~mm}$ diameter transwell filters with a pore diameter of $0.4 \mu \mathrm{m}$ and a surface area of $4.7 \mathrm{~cm}^{2}$ (Costar, Cambridge, MA) were seeded with HT29 $\mathrm{cl} 19 \mathrm{~A}$ cells at a density of $0.8 \times 10^{6} \mathrm{~cm}^{2}$. On reaching confluency, these cells progressively formed a monolayer with the apical and basolateral domains separated by tight junctions. They were studied after 21 days of culture or later, when electrical resistance had stabilised.

\section{RELEASE OF LACTATE DEHYDROGENASE BY HT29 CL 19A CELLS}

Lactate dehydrogenase (LDH) assays were performed by serosally incubating confluent monolayers grown on permeable supports with $1 \%$ or $5 \%$ cytokine rich supernatant. After 24 hours, the culture medium was changed and $200 \mu \mathrm{l}$ were collected in the mucosal compartment of the transwells two hours later, and analysed for LDH. One hundred microlitre samples were added to $0.05 \mathrm{~mol} / \mathrm{l}$ phosphate buffer, $\mathrm{pH} 7.5$ and $3 \cdot 1 \times 10^{-3} \mathrm{~mol} / 1 \mathrm{NADP}^{+}$. The change in absorbance at $340 \mathrm{~nm}$ over five minutes was recorded and LDH activity was calculated with the molar extinction coefficient $6.22 \times 10^{6} .^{11}$ Results are expressed in Ul/h.cm².

\section{MEASUREMENT OF ELECTRICAL PARAMETERS IN} USSING CHAMBERS

Transepithelial potential difference and electrical resistance were measured in cell monolayers as previously described ${ }^{1216}$ under open circuit conditions, and short circuit current was calculated. Filters were gently cut out from the transwell and mounted in small Ussing chambers exposing $0.15 \mathrm{~cm}^{2}$. Each side of the filter was bathed with $1.5 \mathrm{ml}$ of Ringer solution maintained at $37^{\circ} \mathrm{C}$, oxygenated, and circulated by a $95 \% \mathrm{O}_{2}$, $5 \% \mathrm{CO}_{2}$ air lift. Silicon paste was used to minimise edge damage. The mucosal and serosal bathing solutions were connected through $3 M$ $\mathrm{KCl}$ agar bridges to calomel electrodes for measurement of potential differences and to $\mathrm{Ag}-\mathrm{AgCl}$ electrodes for the passage of current through the system. Except when recording short circuit current, filters were maintained under open circuit conditions and pulses of $10 \mu \mathrm{A}$ were periodically applied to the system for electrical measurement of resistance by the deflection of the potential difference. The offset of the electrodes was regularly checked by short circuiting and disconnecting them from the Ussing chamber.

In some experiments, short circuit current was recorded with an automatic voltage clamp (WPI, Newhaven, CT) under short circuit conditions in Ussing chambers exposing $3 \cdot 8 \mathrm{~cm}^{2}$.

\section{FLUX MEASUREMENTS OF HORSERADISH} PEROXIDASE

Horseradish peroxidase (HRP) type VI (Sigma, France) was used as a test macromolecular marker of transcytosis and cell layer integrity as described previously: ${ }^{3} \mathrm{H}$ equivalent HRP fluxes represented both intact and processed peroxidase transport, and intact HRP fluxes were assessed by peroxidase enzymatic activity. ${ }^{13}$ Processing during the passage of HRP across the HT29 $\mathrm{cl}$ $19 \mathrm{~A}$ cells was then calculated as ${ }^{3} \mathrm{H}$ equivalent HRP fluxes minus intact HRP fluxes and referred to as degraded HRP fluxes. The degraded HRP fluxes indicated that the peroxidase transport by the cell monolayer was due to transcytosis as previously shown. ${ }^{4}{ }^{13} 17 \mathrm{~A}$ final concentration of $10 \mu \mathrm{M}(0.4 \mathrm{mg} / \mathrm{ml}) \mathrm{HRP}$, was added to the mucosal compartment, and ${ }^{3} \mathrm{H}$ HRP, prepared and stored as previously reported, ${ }^{13}$ was also added as a tracer $(1.33 \mu \mathrm{Ci} /$ $\mathrm{ml})$. For 130 minutes, $800 \mu \mathrm{l}$ samples were taken from the serosal compartment at 10 and 20 minute intervals and replaced by fresh Ringer solution. Mucosal to serosal intact HRP fluxes were determined by enzymatic assay on $200 \mu \mathrm{l}$ aliquots of serosal samples, according to Maehly and Chance. ${ }^{14}$ The ${ }^{3} \mathrm{H}$ equivalent HRP fluxes were assessed by ${ }^{3} \mathrm{H}$ counting on the remaining $500 \mu \mathrm{l}$ aliquots, with liquid scintillation photometry. Degraded HRP fluxes were then calculated.

STATISTICAL ANALYSIS

Data were analysed with the SAS package (SAS

TABLE I Tumour necrosis factor $\alpha$ (TNF $\alpha)$ interferon $\gamma$ $(I F N \gamma)$ and interleukin 6 (IL6) concentrations in the culture supernatants of control and phytohaemagglutinin (PHA) stimulated lymphocytes from healthy donors

\begin{tabular}{llll}
\hline & $\begin{array}{l}T N F \alpha \\
(n g / m l)\end{array}$ & $\begin{array}{l}I F N \gamma \\
(n g / m l)\end{array}$ & $I L 6(n g / m l)$ \\
\hline $\begin{array}{l}\text { Control cultures } \\
\text { PHA stimulated }\end{array}$ & $0.75(0 \cdot 09)$ & $0 \cdot 40(0 \cdot 09)$ & $0 \cdot 55(0 \cdot 09)$ \\
cultures & $3 \cdot 17(0 \cdot 14)^{\star}$ & $4 \cdot 72(1 \cdot 63)^{\star}$ & $4 \cdot 47(1 \cdot 12)^{\star}$ \\
\hline $\begin{array}{l}{ }^{\star} \mathrm{p}<0.03 \text { by the non-parametric Wilcoxon test. } \\
\text { Results are mean (SE) for four donors. }\end{array}$ &
\end{tabular}


Institute, NC). ${ }^{15}$ Analysis of variance was performed by the general linear model procedure and the non-parametric Wilcoxon test, which were used to compare means and ranges of the different groups of filters. Results are expressed as means (SE).

\section{Results}

CYTOKINE CONTENT OF PHA STIMULATED AND NON-STIMULATED CULTURE SUPERNATANTS There was a significant increase in the concentrations of TNF $\alpha$, IFN $\gamma$, and IL6 in the supernatants of PHA stimulated mononuclear cell cultures compared with those of non-stimulated cultures $(p<0.03$, Table I). The PHA stimulated mononuclear cell supernatants are thus now referred as cytokine rich supernatants (CRS).

\section{SHORT TERM EFFECT OF CRS ON SHORT CIRCUIT} CURRENT

HT29 cl 19A cell monolayers (exposed area $3.8 \mathrm{~cm}^{2}$ ) placed in an Ussing chamber had a short circuit current of $6.79(0.65) \mu \mathrm{A} / \mathrm{cm}^{2}$ and a potential difference of $0.99(0.09) \mathrm{mV}$ and their resistance was $158(10)$ ohms. $\mathrm{cm}^{2}(\mathrm{n}=44)$. When stimulated on their serosal side with cytokine rich supernatant at a final concentration of $1 \%$ or $5 \%$, short circuit current did not change (Fig 1). Cells were able to develop a secretory response, however, after stimulation with $10^{-6} \mathrm{M}$ pros-

Figure 1: Typical recording of short circuit current from a HT29 $\mathrm{cl} 19 \mathrm{~A}$ cell monolayer (exposed area $\left.=3 \cdot 8 \mathrm{~cm}^{2}\right)$ successively stimulated with cytokine rich culture supernatant (at 1\% concentration) and $P G E_{2}$ as a secretagogue. Cytokine rich culture supernatants used at $5 \%$ concentration gave the same pattern (not shown).

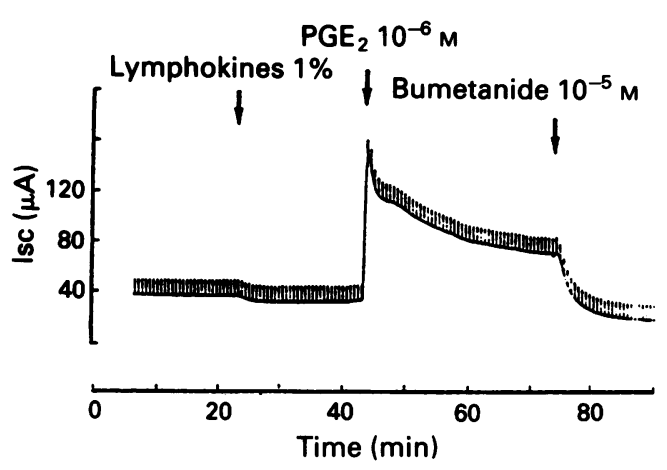

TABLE II Long term effects of lymphocyte culture supernatants on electrical parameters of HT29 cl 19 A cell monolayers

\begin{tabular}{|c|c|c|c|c|c|}
\hline \multirow{2}{*}{$\begin{array}{l}\text { Supernatant } \\
\text { concentrations } \\
\text { (Incubation time) }\end{array}$} & \multirow{2}{*}{$\begin{array}{l}0 \% \\
(O h)\end{array}$} & \multicolumn{2}{|l|}{$1 \%$} & \multicolumn{2}{|l|}{$5 \%$} \\
\hline & & $(2 h)$ & $(48 h)$ & $(2 h)$ & $(48 h)$ \\
\hline $\begin{array}{l}\text { Short circuit current } \\
\left(\mu \mathrm{A} / \mathrm{cm}^{2}\right) \\
\text { Potential difference } \\
(\mathrm{mV}) \\
\text { Resistance } \\
\left(\text { ohms. } \mathrm{cm}^{2}\right)\end{array}$ & $\begin{array}{l}6.79(0.65) \\
(n=44) \\
0.99(0.09) \\
(n=44) \\
158(10) \\
(n=44)\end{array}$ & $\begin{array}{l}4 \cdot 13(0 \cdot 64) \\
(n=7) \\
0 \cdot 46(0 \cdot 06)^{\star \star} \\
(n=7) \\
125(23) \\
(n=7)\end{array}$ & $\begin{array}{l}3 \cdot 88(0 \cdot 97)^{\star} \\
(n=8) \\
0 \cdot 28(0 \cdot 10)^{\star \star} \\
(n=15) \\
69(9)^{\star \star} \\
(n=8)\end{array}$ & $\begin{array}{l}8 \cdot 41(1 \cdot 12) \\
(n=8) \\
0 \cdot 90(0 \cdot 12) \\
(n=8) \\
111(5)^{\star} \\
(n=8)\end{array}$ & $\begin{array}{l}2 \cdot 90(1 \cdot 16)^{\star \star} \\
(n=15) \\
0 \cdot 11(0 \cdot 05)^{\star \star} \\
(n=15) \\
36(9)^{\star \star} \\
(n=15)\end{array}$ \\
\hline
\end{tabular}

${ }^{\star} \mathrm{p}<0.05 ;{ }^{\star \star} \mathrm{p}<0.01$, significantly different from control.

Results are mean (SE).

TABLE III Lactate dehydrogenase ( $L D H)$ release by $H T 29 \mathrm{cl} 19 \mathrm{~A}$ cells treated with cytokine rich supernatant $(C R S)$

\begin{tabular}{llllll}
\hline & Controls & $\begin{array}{l}1 \% \text { PHA } \\
\text { controls }\end{array}$ & $\begin{array}{l}5 \% \text { PHA } \\
\text { controls }\end{array}$ & $1 \%$ CRS & $5 \%$ CRS \\
\hline LDH $\left(\mathrm{UI} / \mathrm{h} . \mathrm{cm}^{2}\right)$ & $12 \cdot 1(2 \cdot 1)$ & $10 \cdot 6(1 \cdot 7)$ & $12 \cdot 6(5 \cdot 9)$ & $24 \cdot 3(1 \cdot 4)^{\star}$ & $48.9(2 \cdot 3)^{\star \star}$
\end{tabular}

${ }^{\star} \mathrm{p}<0.001 ;{ }^{\star \star} \mathrm{p}<0.0001$, significantly different from controls.

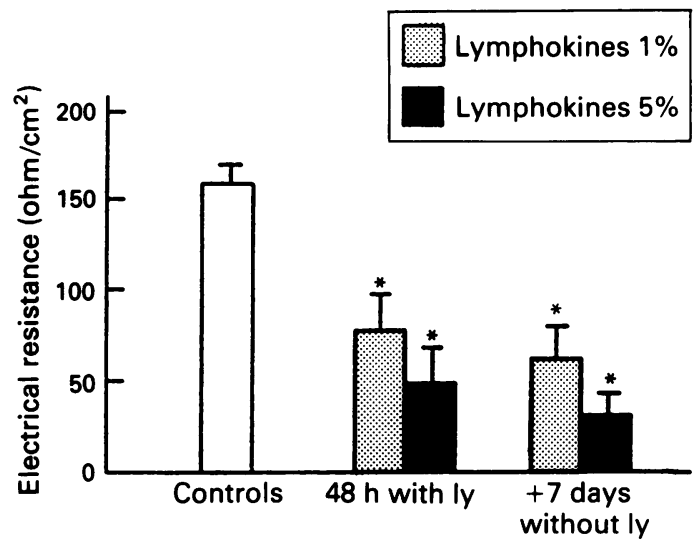

Figure 2: Lack of reversibility of the decrease in electrical resistance in $H T 29 \mathrm{cl} 19 \mathrm{~A}$ cell monolayers exposed to cytokine rich culture supernatants at a concentration of $1 \%$ or $5 \%$ for 48 hours and returned to control conditions over seven days (ly=lymphokines).

taglandin E2 (change in short circuit current $=32$ $\mu \mathrm{A} / \mathrm{cm}^{2}$ ), as indicated by the increase in short circuit current that can be inhibited by bumetanide. These results indicate that cytokines do not directly stimulate chloride secretion in HT29 cl 19A cells.

LONG TERM EFFECT OF CRS ON ELECTRICAL

PARAMETERS OF HT29 CL 19A CELLS

Before testing the long term effect of short circuit current, potential difference, and resistance, control experiments were run to ensure that neither the non-activated mononuclear cell culture supernatants nor the PHA they contained had any toxic effect on the HT29 cl 19A cell monolayers. When paired control HT29 $\mathrm{cl} 19 \mathrm{~A}$ cell monolayers were incubated with nonactivated mononuclear cell culture supernatants containing PHA at similar periods and at similar concentrations, there were no significant differences between their short circuit current, potential difference, or resistance values and those of non-treated cell monolayers. Therefore, control values were taken as the means of all paired control conditions.

As reported in Table II, a progressive decrease in short circuit current, potential difference, and resistance was found as a function of the duration of the serosal exposure of the monolayers. In particular, after 48 hours of exposure, the

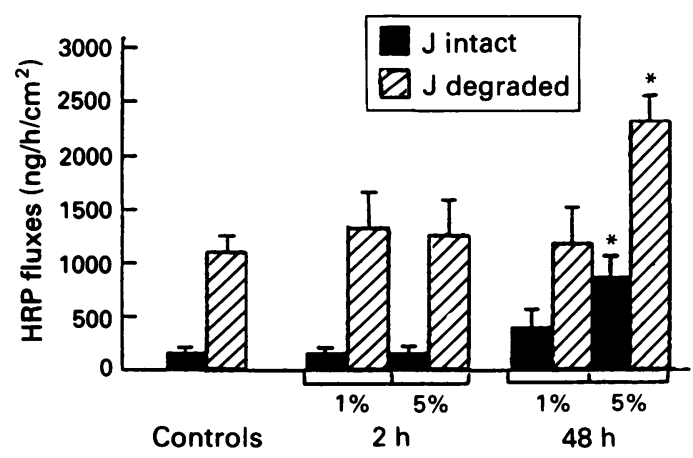

Figure 3: Time and concentration dependent effects of cytokine rich culture supernatants on horseradish peroxidase (HRP) fluxes in intact (black bars) and degraded form (hatched bars). 
decrease in resistance was related to the concentration of the cytokine rich supernatant $(69$ (9) and $36(9) \mathrm{ohms}^{\circ} \mathrm{cm}^{2}$ in HT29 cl 19A cell monolayers treated with supernatant concentrations of $1 \%$ and $5 \% v 158(10)$ in controls) and suggested paracellular leakage. This decline in resistance was not reversible, even one week after the return to standard culture conditions (Fig 2).

\section{RELEASE OF LDH BY HT29 CL 19A CELLS TREATED} WITH CYTOKINE RICH SUPERNATANT

Table III shows release of LDH by HT29 $\mathrm{cl} 19 \mathrm{~A}$ cells in different conditions. The basal release of LDH from HT29 cl 19A monolayers was not statistically different from controls incubated with PHA at $1 \%$ or $5 \%$. The serosal addition of $1 \%$ and $5 \%$ CRS significantly increased LDH release suggesting HT29 cl 19A cell damage.

\section{EFFECT OF CYTOKINE RICH SUPERNATANT ON HT29 CL 19A CELL MONOLAYER PERMEABILITY TO HORSERADISH PEROXIDASE}

Short term exposure of monolayers for two hours to cytokine rich supernatant did not modify intact or degraded HRP transport (Fig 3), even at the high supernatant concentration of $5 \%$, when electrical resistance slightly decreased. After 48 hours of serosal exposure, however, there was an increase in intact HRP fluxes and a significant increase in degraded HRP fluxes at this concentration, indicating both a decrease in the barrier capacity and a higher rate of transcytosis. Under control conditions, less than $10 \%$ of the HRP crossed the monolayer in the intact form as previously reported ${ }^{16}{ }^{17}$ but in supernatant stimulated cells, this proportion rose to $25 \%$, further suggesting a reduction in the barrier capacity of the HT29 cl 19A monolayer to intact proteins.

\section{Discussion}

These results indicate that cytokines have deleterious long term effects on the electrogenic properties and barrier capacity of the intestinal epithelium. Intestinal malfunction and permeability disturbances often occur during intestinal inflammatory reactions, and the direct effect of the cytokines released within the lamina propria by activated immune cells is poorly understood. In particular, our attention focused on the intestinal manifestations of cow's milk allergy in infants. In jejunal biopsies from such children, taken before milk exclusion from their diet, we found an increased macromolecular transport and enhanced short circuit current (that reflects $\mathrm{Cl}^{-}$secretion), together with noticeable lymphocyte infiltration of the lamina propria. ${ }^{4}$ As most of these infants had no immediate type I IgE related hypersensitivity, their impaired intestinal function was probably due to lymphocyte activation and delayed hypersensitivity. It thus seemed interesting to establish whether or not the cytokines released within the lamina propria by stimulated lymphocytes were responsible for such abnormalities of transport.

In a first attempt to answer this question, we used mononuclear cells from peripheral blood of healthy donors. These were stimulated non- specifically with PHA, and we tested the effect of culture supernatants of these cells on epithelial function, with the human intestinal cell line HT29 cl 19A.

Whether the nature of the peripheral mononuclear cell population accurately reflects what occurs in the lamina propria is an important question. After antigenic stimulation, lymphocytes have to migrate from the lymphoid tissues associated with the gut where they are primed, to their final mucosal homing sites (via the lymph nodes, lymph, and peripheral blood) where they mature. Therefore, at least some of the peripheral blood lymphocytes are representative of what happens within the intestinal mucosa, and these lymphocytes were previously used to measure the intestinal immune response..$^{1819}$ Furthermore, recent studies have shown that activated lamina propria lymphocytes secreted mostly TNF $\alpha$ and IFN $\gamma .{ }^{8}$ Both these cytokines are also abundantly released by PHA activated peripheral blood lymphocytes. We used a human intestinal cell line rather than intestinal biopsy specimens or fragments because it constitutes reproducible human material that is easily accessible to investigation and well adapted to long term studies, whereas biopsies are difficult to maintain in good condition for the time necessary to conduct such long term studies. Also, the HT29 cl 19A cell line is known to possess secretory capacities, and in particular, to secrete $\mathrm{Cl}^{-}$in response to different stimuli ${ }^{20}$; it is therefore an appropriate model for the study of diarrhoea.

In our work, the absence of any immediate effect of cytokine rich supernatants on the secretion of $\mathrm{Cl}^{-}$by HT29 $\mathrm{cl} 19 \mathrm{~A}$ cells was confirmed by the absence of an increase in short circuit current when the cells were serosally exposed to these supernatants. This result strengthens the previously formulated hypothesis that the cytokines ILl and IL3 stimulate short circuit current by the secondary release of secretagogues such as prostaglandin $\mathrm{E}_{2}$, because in rabbit ileal mucosa, IL1 stimulated short circuit current was inhibited by the arachidonic acid metabolism inhibitors indomethacin and piroxicam. ${ }^{6}$ This hypothesis was also strengthened by studies of mucosal strips of chicken intestine, in which these cytokines stimulated the release of prostaglandin $E_{2}$ and raised the cAMP concentration, ${ }^{5}$ and by studies of IL1 induced eicosanoid production in the rabbit colon and many other cell types including endothelial cells, synovial cells, chondrocytes, and fibroblasts. ${ }^{21}$

Although no immediate electrogenic effect was induced by short term exposure of HT29 $\mathrm{cl} \mathrm{19A}$ cells to cytokine rich supernatants, a prolonged exposure of two hours in the transwell culture plates, before the measurements in Ussing chambers, significantly reduced both short circuit current and potential difference but did not alter resistance suggesting cellular dysfunction in capacity to absorb electrolytes, probably due to alterations in ionic exchanges in the membrane. These results are comparable with those of previous work showing that long term incubation with IFN $\gamma$ reduced $\mathrm{Cl}$ secretion in response to various secretagogues. ${ }^{22}$ After 48 hours, electrical resistance - that is, barrier capacity - also 
decreased, confirming the degradation of cell to cell tight junctions, which are mainly responsible for electrical resistance in this epithelial model. This decrease in barrier capacity was confirmed by the rise in intact HRP fluxes, probably through a paracellular pathway and by an increased intact/total HRP transport ratio $(25 \%$ v $13 \%$ in treated $v$ control monolayers). A similarly reduced barrier capacity was also reported in T84 intestinal cells after exposure to IFN $\gamma .^{7}$ The results of various studies have strengthened the concept that cytokines, especially $\mathrm{TNF} \alpha$ and IFN $\gamma$, might act synergistically to induce noxious effects. ${ }^{8}$ In our study, PHA activated mononuclear cells released both TNF $\alpha$ and IFN $\gamma$ so that both are possible inducers of the noted effects. The cytokine rich supernatant increased $\mathrm{LDH}$ release further indicated that some damage had occurred at the cellular level. It is, however, important to note that degraded HRP transport also increased, indicating that the rate of endocytosis was stimulated by prolonged exposure to cytokines. Therefore, the transcellular transport capacity seems to be maintained in HT29 cl 19A cells, which might exclude the possibility of their lysis, due to the effect of cytokines.

Taken together, these results suggest that activated mononuclear lymphoid cells might be implicated in intestinal malfunction and permeability disturbance found during intestinal inflammatory reactions.

We thank Dr Dugas (EIBET-BIOANOVA) assay of IL6, IFN $\gamma$, and TNF $\alpha$ in lymphocyte supernatants and Mrs Dreyfus for editing the manuscript. This work was supported in part by the Institut National de la Santé et de la Recherche Médicale, by the Ministére de la Recherche et de la Technologie, Grant n' ${ }^{\circ}$ 90G0263, and by the Mutuelle Générale de e'éducation Nationale M GEN and by the Mutuelle

This work was partially presented at the XXIV annual meeting This work was partially presented at the XXI
of the ESPGAN, 5-7 June 1991, London, UK

1 Bern MJ, Sturbaum CW, Karayalcin SS, Bershneider HM, Wachsman JT, Powell DW. Immune system control of rat and rabbit colonic electrolyte transport. F Clin Invest 1989; 83: $1810-20$.
2 Crowe SE, Sestini P, Perdue MH. Allergic reactions of rat jejunal mucosa, ion transport responses to luminal antigen and inflammatory mediators. Gastroenterology 1990; 99. $74-82$.

3 Perdue MH, Masson S, Wershil BK, Galli SJ. Role of mast cells in ion transport abnormalities associated with th intestinal anaphylaxis. F Clin Invest 1991; 87: 687-93.

4 Heyman M, Grasset E, Ducroc R, Sesjeux JF. Antigen absorption by the jejunal epithelium of children with cow's milk allergy. Pediatr Res 1988; 241: 197-202.

5 Chang EB, Musch MW, Mayer L. Interleukins 1 and 3 stimulate anion secretion in chicken intestine. Gastroenterology 1990; 98: 1518-24.

6 Chiossone DC, Simon PL, Smith PL. Interleukin 1: effects on rabbit ileal mucosal ion transport in vitro. Eur $\mathcal{F}$ Pharmacol 1990; 180: 217-28.

7 Madara JL, Stafford J. Interferon-gamma directly affects barrier function of cultured intestinal epithelial monolayers. barrier function of cultured in

8 Deem RL, Shanahan F, Targan SR. Triggered human mucosal $T$ cells release tumour necrosis factor-alpha and interferon-gamma which kill human colonic epithelial cells. Clin Exp Immunol 1991; 83: 79-84.

9 Augeron C, Laboisse CL. Emergence of permanently differentiated cell clones in a human colonic cell line in culture after treatment with sodium butyrate. Cancer Res 1984; 44: 3961-9.

10 Chen TR. In situ detection of mycoplasma contamination in cell cultures by fluorescent Hoechst 33258 stain. Exp Cell Res 1977; 104: 255-62.

11 Bergmeyer HU, Bernt E, Hess B. Lactic deshydrogenase. In Bergmeyer HU, ed, Methods of enzymatic analysis. New Bergmeyer HU, ed, Methods of

12 Grasset E, Pinto M, Dussault E, Zweibaum A, Desjeux JF Epithelial properties of the human colonic carcinoma cellline Caco-2: electrical parameters. Am F Physiol 1984; 247 $\mathrm{C} 260-7$

13 Heyman M, Ducroc R, Desjeux JF, Morgat JL. Horseradish peroxidase transport across adult rabbit jejunum in vitro. Am F Physiol 1982; 242: G558-64.

14 Maehly AC, Chance B. The assay of catalases and peroxidases. In: Glick D, ed. Methods of biochemical analysis 1954; 1: 357-98.

15 SAS Institute. Guide for personal computers. G ed. Cary, NC SAS Institute, 1985.

16 Heyman M, Crain-Denoyelle AM, Nath SK, Desjeux JF. Quantification of protein transcytosis in the human colon

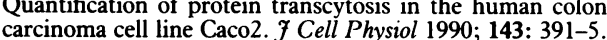

17 Heyman M, Desjeux JF. Significance of intestinal food protein transport. F Pediatr Gastroenterol Nutr 1992; 15: 48-57.

18 Forrest BD. Identification of an intestinal immune respons using peripheral blood lymphocytes. Lancet 1988; 1: 81-8.

9 Isolauri E, Virtanen E, Jalonen T, Arvilommi H. Loca immune response measured in blood lymphocytes reflects the clinical reactivity of children with cow's milk allergy. Pediatr Res 1990; 28: 582-6.

20 Nath SK, Huang X, L'Helgouac'h A, Rautureau M, Bisalli A, Heyman $M$, et al. Time-relationship between chloride secretion and intracellular messengers in HT29 HT29 cl $19 \mathrm{~A}$ epithelial cells stimulated by cholera toxin. Gastroenterology 1991; 100: A604.

21 Cominelli F, Nast CC, Dinarello CA, Gentilini P, Zipser RD. Regulation of eicosanoid production in rabbit colon by interleukin-1. Gastroenterology 1989; 97: 1400-5.

22 Holmgren J, Fryklund J, Larsson H. Gamma-interferonmediated down-regulation of electrolyte secretion by intestinal epithelial cells: a local immune mechanism? Scand $\mathcal{f}$ Immunol 1989; 30: 499-503. 